Review

\title{
Current Status and Future Prospects of Applying Bioinspired Superhydrophobic Materials for Conservation of Stone Artworks
}

\author{
Yijian Cao ${ }^{1,2}$, Antonella Salvini ${ }^{2}$ and Mara Camaiti ${ }^{1, *}$ \\ 1 CNR-Institute of Geosciences and Earth Resources, Via Giorgio La Pira 4, 50121 Florence, Italy; \\ yijian.cao@unifi.it \\ 2 Department of Chemistry, University of Florence, Via della Lastruccia 3-13, 50019 Sesto Fiorentino (FI), Italy; \\ antonella.salvini@unifi.it \\ * Correspondence: mara.camaiti@igg.cnr.it; Tel.: +39-055-2757558
}

Received: 6 February 2020; Accepted: 2 April 2020; Published: 4 April 2020

\begin{abstract}
The development of innovative materials is one of the most important focus areas in heritage conservation research. Eligible materials can not only protect the physical and chemical integrity of artworks but also preserve their artistic and aesthetic features. Recently, as one of the hot research topics in materials science, biomimetic superhydrophobic materials have gradually attracted the attention of conservation scientists due to their unique properties. In fact, ultra-repellent materials are particularly suitable for hydrophobization treatments on outdoor artworks. Owing to their excellent hydrophobicity, superhydrophobic materials can effectively prevent the absorption and penetration of liquid water as well as the condensation of water vapor, thus greatly relieving water-induced decay phenomena. Moreover, in the presence of liquid water, the superhydrophobic surfaces equipped with a self-cleaning property can clean the dirt and dust deposited spontaneously, thereby restoring the artistic features simultaneously. In the present paper, besides the basic principles of wetting on solid surfaces, materials, and methods reported for preparing bioinspired ultra-repellent materials, the recently proposed materials for art conservation are also introduced and critically reviewed, along with a discussion on the droplet impact and durability of the artificial superhydrophobic surfaces. Lastly, the current status and the problems encountered in practical application are also pointed out, and the focus of future research is presented as well.
\end{abstract}

Keywords: superhydrophobic coatings; self-cleaning; stone artworks; conservation; future prospect

\section{Introduction}

Surface water inhibition treatment is an indispensable action that has been widely used for the conservation and restoration of various types of artworks which include stones, ceramics, mortars, woods, bronzes, etc., since liquid water has been regarded as one of the most fundamental causes accounting for their degradation. Taking stone objects for example, liquid water not only causes the dissolution of water-soluble components inside stones but also induces or promotes other water-related decay phenomena, such as freeze/thaw cycles [1], salt crystallization [2], and deposition of atmospheric contaminants [3], leading to increased bioreceptivity and susceptibility towards biological colonization $[4,5]$ and so on. Under outdoor conditions, with the impact of other environmental factors, e.g., atmospheric pollutants, spores, infamous black crusts, and microorganism colonization, corrosion and decohesion phenomena are commonly observed on stone heritage materials (Figure 1). In order to halt or slow down stone degradation, hydrophobic surfaces are universally required.

By definition, protection is an active treatment that is operated directly on objects, providing hydrophobic properties as well as resistance to deterioration agents (e.g., pollution, microorganisms 
etc.) without reducing the original vapor permeability [6]. As nowadays there are extensively large quantities of natural and synthetic substances available on the market, a series of criteria shall be considered when selecting appropriate products. According to standard recommendation [7], the essential requirements for a substance to be considered a protective agent for stone artifacts include (1) hydrophobicity; (2) good adhesion to stone substrates; (3) good permeability to water vapor; (4) good chemical and physical compatibility with stone substrates; (5) good chemical, physical, thermal, and photo-oxidative stability; (6) good solubility of environmentally benign and healthy solvents; (7) no perceivable color change of substrates; (8) reversibility, etc. As a matter of fact, the history of surface treatment conducted on stone objects dates back to ancient Greek and Roman periods, when natural materials such as oils and waxes were used for protection and polishing purposes $[8,9]$. With the advance of science and technology, since the second half of the 20th century, synthetic polymeric materials have completely replaced by natural resins in stone protection [9]. The main reasons for their popularity are their diversity in type and range of applications and the possibility of individualised or performance-oriented adjustment during production [9]. Acrylic resins, silicon-based resins, microcrystalline waxes, perfluoropolyethers (PFPEs), polyfluorourethanes, fluorinated polymers, and fluoroelastomers are the representative compounds [8-13]. Recently, starting from the 21st century, some innovative materials such as structurally modified acrylic polymers and PFPEs, organic-inorganic hybrids, nano-scaled and microemulsions of some polymers, and nanoparticle composites, etc., have being proposed and tested [14-20]. These products usually show good chemical and physical compatibility, good adhesion, and good solubility, and in some cases a good consolidation effect $[9,10,16]$. Yet, they also have drawbacks in long-term use (e.g., low photo-oxidative stability, biodegradation, irreversibility) [10,16,21-24]. In particular, their hydrophobicity and performance durability are not sufficient for protecting stones in outdoor environments, as black crusts, dust, dirt depositions, and biological growth are frequently seen on some coated stone statues, buildings, mortars, etc. [25].

Nature is an unexhaustive source in inspiring humans to accomplish new scientific and/or technological achievements. Observing the unique wetting and antiwetting phenomena in nature, e.g., water rolling off lotus leaves [26], dew, rain, nonwettable and dust-free cicada wings [27], dirt-free gecko feet [28], water pinned on rose petals [29], etc., ultra repellent surfaces have attracted great interest in academic and industrial fields. Over the last two decades, artificial surfaces with "lotus effect" or "rose petal effect" properties have been studied, and many successful biomimicing surfaces have been prepared [30-34]. Among the two broad types of super-antiwetting materials, surfaces with "lotus effects" [high static water contact angle $\left(\mathrm{CA}>150^{\circ}\right)$ and low contact angle hysteresis $\left(\mathrm{CAH}<10^{\circ}\right)$ ] have gained more attention, owing to their great value in both theoretical research and functional application in fields such as self-cleaning, anti-biofouling, anti-icing, oil/water separation, etc. [35-41]. In fact, ultra water-/oil-repellent surfaces equipped with a self-cleaning property are also the most ideal materials for protecting building stones which are exposed to open air, since they can well preserve the chemical and physical integrity of substrates while conserving the artistic features at the same time.

In this review, the basic principles of different wetting phenomena on solid surfaces and the definition of superhydrophobicity are introduced briefly. The most widely used fabrication materials and methods, along with the pros and cons of these proposed materials/methods for stone conservation, are described and critically reviewed. A description of the droplet impact on solid surfaces and the wetting property stability of the superhydrophobic surfaces are also reported and critically discussed. Last but not least, the obstacles that need to be tackled in achieving superhydrophobic surfaces practically and the perspectives on future research (in both materials synthesis and application) are also presented. 

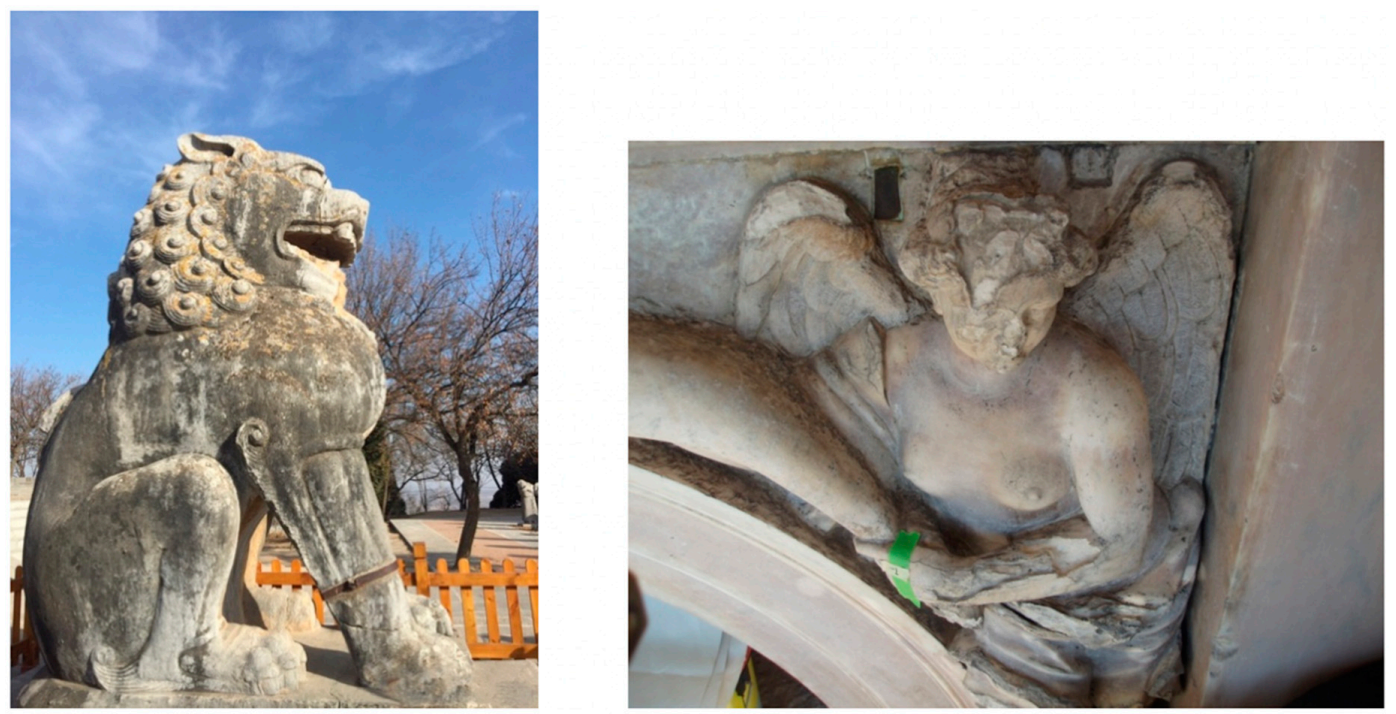

Figure 1. Examples of stone artifacts with typical black crust, biological colonization, and decohesion phenomena.

\section{Basic Principles of Wetting States and Superhydrophobicity}

\subsection{Wetting Properties and Basic Models}

As a common interface phenomenon, the wetting of a solid surface by a liquid is mainly determined by the microstructure of the solid surface and the surface chemical composition (surface free energy) [27,30]. CA quantifies the wettability of a solid surface by a liquid via Young's equation (Equation (1), Figure 2), where $\gamma$ is the interfacial tension, subscripts SV, SL, and LV denote the solid-vapor (gas), solid-liquid, and liquid-vapor (gas) interfaces, respectively, and $\theta_{Y}$ (Young's CA) is the equilibrium CA at the three-phase point [42]. Surfaces are defined as hydrophilic when the water CA is less than $90^{\circ}$. If the CA ranges from $90^{\circ}$ to $150^{\circ}$, the surface is hydrophobic, while surfaces are superhydrophobic when $\mathrm{CA}>150^{\circ}$ [43].

$$
\gamma_{\mathrm{LV}} \cos \theta_{\mathrm{Y}}=\gamma_{\mathrm{SV}}-\gamma_{\mathrm{SL}}
$$

\subsubsection{Smooth Surface}

Young's equation is an ideal model for perfectly smooth surfaces, since it neglects the influence of surface roughness, chemical heterogeneity, surface reconstruction swelling, and dissolution, etc., which do affect the wetting phenomenon. Among these factors, surface roughness is regarded as one of the most influential parameters on CA [44,45]. Two models, i.e., the Wenzel model and Cassie-Baxter model, were developed later and generally employed to correlate surface roughness with apparent CA.

\subsubsection{Rough Surface}

In the Wenzel cases (Equation (2)), surface roughness factor $r$ is considered (Equation (3)), since it assumes the droplet follows the rough surface and fills in the asperities (Figure 2b) [44]. The roughness factor amplifies the effect of surface chemistry determined by $\cos \theta$. When $\theta_{Y}<90^{\circ}$, an increase in $r$ reduces the apparent $C A\left(\theta_{\mathrm{w}}\right.$, Wenzel CA), while if $\theta_{Y}>90^{\circ}$, an increase in $\mathrm{r}$ results in an increase in $\theta_{\mathrm{w}}$. This means a hydrophilic surface will become more hydrophilic when its surface is rougher, whereas a hydrophobic surface will be more hydrophobic when its surface is roughened. In general, droplets in the Wenzel state show strong adhesion to surfaces. Yet, for some surfaces, such as highly 
rough or porous structures, the absolute value of the right side of Equation (2) might be larger than 1 . In such cases, the Wenzel model is not valid, and the Cassie model will be used.

$$
\begin{gathered}
\cos \theta_{\mathrm{W}}=\mathrm{r} \cos \theta_{\mathrm{Y}} \\
\mathrm{r}=\frac{\text { actual surface area }}{\text { planar surface area }}
\end{gathered}
$$

In the Cassie model, the droplet suspends on the surface and it does not penetrate into cavities (Figure 2c) [45]. Air pockets are assumed to be trapped in asperities. In this state, the apparent $C A\left(\theta_{c}\right.$, Cassie-Baxter CA) is the result of contributions of varied phases (Figure 2c, Equation (4)):

$$
\cos \theta_{\mathrm{C}}=\mathrm{f}_{\mathrm{SL}} \cos \theta_{\mathrm{s}}+\mathrm{f}_{\mathrm{LV}} \cos \theta_{\mathrm{v}}
$$

where $\mathrm{f}_{\mathrm{SL}}$ and $\mathrm{f}_{\mathrm{LV}}$ are the surface fractions of solid-liquid and liquid-vapor interfaces, respectively, with $\theta_{\mathrm{S}}=\theta_{\mathrm{W}}$. If only one type of protrusion (which means homogeneous roughness) is present, $\mathrm{f}_{\mathrm{SL}}+\mathrm{f}_{\mathrm{LV}}=1$ and $\theta_{\mathrm{v}}=180^{\circ}$; Equation (4) becomes:

$$
\cos \theta_{\mathrm{C}}=\mathrm{f}_{\mathrm{SL}}\left(1+\cos \theta_{\mathrm{W}}\right)-1
$$

In the Cassie-Baxter model, $\theta_{\mathrm{c}}$ of either an inherently hydrophilic or hydrophobic material increases with roughness, and $\theta_{\mathrm{c}}$ can therefore become larger than $150^{\circ}$ for any material. Consequently, the Cassie model suggests that roughness enhances the hydrophobic character of a surface with either inherent hydrophilicity or hydrophobicity. Surfaces wetted in the Cassie state are usually slippery than those in the Wenzel state, which are sticky. Wenzel and Cassie define the two limits of wetting behaviors, and surfaces may also show an intermediate state or the Wenzel-Cassie state. In this situation, apparent $\mathrm{CA}$ is affected by both solid-surface fraction $\mathrm{f}_{\mathrm{SL}}$ and roughness factor $\mathrm{r}$. Combining Equations (2) and (5), the apparent CA in intermediate states is described by Equation (6):

$$
\cos \theta_{\mathrm{C}}=\mathrm{f}_{\mathrm{SL}}\left(\mathrm{r} \cos \theta_{\mathrm{Y}}+1\right)-1
$$

In reality, the starting solid-liquid contact model (i.e., Cassie-Baxter model) does not persist forever. A transition from the Cassie to Wenzel state is observed under external stimulus, such as droplet impact pressure, or vibration [46-49]. Droplets pinned on rose petals are in the Cassie impregnating wetting state in which water penetrates into cavities [50]. The transition or coexistence of these two models was visualized by a large-scale molecular dynamic simulation method, as reported by Zeng et al [51].

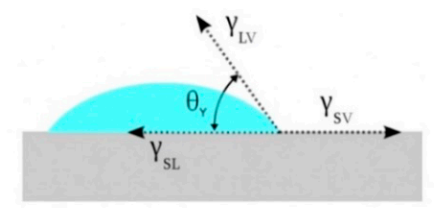

(a)

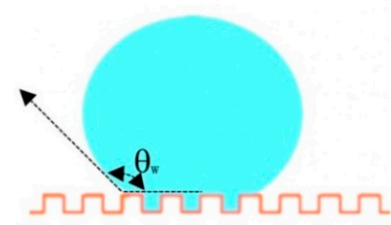

(b)

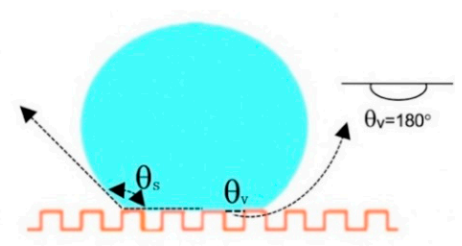

(c)

Figure 2. Typical wetting behavior of a droplet on a solid surface: (a) Young's model; (b) Wenzel's model; (c) Cassie's model. 


\subsubsection{Dynamic Wetting Behaviors}

In real cases, to characterize the wetting properties of solid-liquid interfaces only by CA is not enough. CAH (contact angle hysteresis) and SA (sliding angle) are therefore introduced. When a droplet is inflated, CA will increase but the contact area will not change until $\theta_{\text {adv }}$ (advancing contact angle) reaches a critical value and then it begins to advance. Similarly, if a droplet is deflated, there is also a critical value called the receding angle $\left(\theta_{\text {rec }}\right)$ that must be reached before the contact line begins to recede. By definition, the difference between $\theta_{\mathrm{adv}}$ and $\theta_{\mathrm{rec}}$ is termed CAH. Surfaces with low $\mathrm{CAH}$ allow drops to slide over them easily (Cassie state), regardless of the equilibrium CA. On the contrary, surfaces wetted in the Wenzel state show high $\mathrm{CAH}$, and drops are adhered onto them. The quantitative relationship between CAH and SA is governed by Equation (7) [52]:

$$
\mathrm{mg} \sin \alpha=\gamma_{\mathrm{LV}} \mathrm{W}\left(\cos \theta_{\mathrm{rec}}-\cos \theta_{\mathrm{adv}}\right)
$$

where $g$ is the gravity force, $\alpha$ is the tilt angle (or SA) while $\mathrm{m}$ and $\mathrm{w}$ represent the mass and width of the drop, respectively. For a water drop with fixed mass, the amount $\gamma_{\mathrm{LV}} \mathrm{w} / \mathrm{mg}$ in Equation (7) is constant, and therefore SA for the Cassie model surfaces will be smaller than that for the Wenzel one. For slippery superhydrophobic surfaces (droplets in the Cassie model), their CAH is usually smaller than $10^{\circ}$. As CAH is a measure of energy dissipation during droplet movement, the solid surface energy $\left(\sigma_{\mathrm{s}}\right)$ can also be estimated exploiting CAH (Equation (8)) [53]:

$$
\sigma_{\mathrm{S}}=\frac{\sigma_{\mathrm{LV}}\left(1+\cos \theta_{\mathrm{adv}}\right)^{2}}{2+\cos \theta_{\mathrm{adv}}+\cos \theta_{\mathrm{rec}}}
$$

where $\sigma_{\mathrm{LV}}$ is the water surface tension $(72.8 \mathrm{mN} / \mathrm{m})$. For superhydrophobic surfaces, the surface energy is significantly smaller than $72.8 \mathrm{mN} / \mathrm{m}$.

\section{Fabrication of Superhydrophobic Surfaces}

Based on the principle of surface hydrophobicity, the wettability of a material is determined by its surface free energy and surface roughness. At present, there are two main strategies for preparing superhydrophobic materials: (a) to construct microscopic roughness on the surface of a hydrophobic material; (b) to add a layer of substance with low surface energy to the surface of a microscopically rough material $[30,31,33]$. In summary, surface roughness at the microscopic scale (nano-, sub-micrometre) and low surface energy compounds are two essential conditions for obtaining superhydrophobic surfaces.

\subsection{Chemicals}

There are many types of raw compounds used for the synthesis of ultra-repellent materials, including organic, inorganic, and organic-inorganic composite materials. Here, we mainly focus on the superhydrophobic materials synthesized with the purpose to protect stone heritage materials, for which raw compounds such as organosilanes, siloxanes, silane-coupling agents, $\mathrm{SiO}_{2}$ and $\mathrm{TiO}_{2}$ nanoparticles, fluorine-containing materials, etc., are often employed.

In spite of the numerous chemicals available, silanes and silicones play very important roles in the preparation of ultra-repellent surfaces. Approximately 25\% of the literature about superhydrophobic and superoleophobic materials is based on silanes and silicones [54]. They are frequently used for constructing appropriate surface topography and decreasing the surface energy and act as binders to link building blocks together or to bind materials of low surface energy to substrates [54]. In fact, the alkyl groups of silanes are mainly used to decrease the surface tension while the hydrolyzable groups, e.g., $\mathrm{Si}-\mathrm{Cl}, \mathrm{Si}-\mathrm{NH}-\mathrm{Si}, \mathrm{Si}-\mathrm{OR}$, could react with water to form silanols. The silanols firstly could condense with other hydroxyl groups at the surface of substrates, while the remaining silanols may self-condense to form a unique micro/nanostructured silicone layer. Thus, there is much scope for 
tailoring the properties of the coatings by changing the hydrolyzable and alkyl groups of silanes and the reaction conditions [55].

\subsubsection{Silica Nanoparticles}

A common strategy to construct super-antiwetting surfaces is to use silica nanoparticles (NPs) to create micro/nanostructures and then modify them with low surface tension materials. Ethylene polymerized over self-assembled silica NPs [56], a perfluoroalkyl methacrylic copolymer coated on a hierarchical nano/submicron silica spheres stacking layer [57], poly(4-vinylpyridine)-b-polystyrene diblock copolymer surrounded on a silica core- [58] or a hydrophobic ionic liquid and negatively charged silica NPs alternatively absorbed onto glass substrates via layer-by-layer self assembly [59] are only some examples that show the fabrication of superhydrophobic surfaces.

\subsubsection{Polydimethylsiloxane (PDMS)}

Super-repellent surfaces can also be prepared by constructing micro-/nano-structures via rough PDMS surfaces. Two methods can be exploited to fabricate superamphiphobic surfaces based on PDMS: one involves PDMS surface roughening followed by surface modification with low surface energy compounds, while in the second method, the hydrophobic properties of PDMS are enhanced by direct surface roughening. In the first method, rough PDMS surfaces can be formed by soft lithography, plasma etching, $\mathrm{H}_{2} \mathrm{O}_{2}$ etching or their combination [54]. Robust superhydrophobic PDMS surfaces with fully controlled wetting properties and geometrical characteristics have been obtained via roughening of $\mathrm{PDMS}_{\text {in }} \mathrm{SF}_{6}$ plasma followed by plasma-induced fluorocarbon film deposition $[60,61]$. PDMS can also be used to negatively replicate the surface texture of plant leaves (e.g., lotus leaves) or, more generally, manmade surfaces (e.g., patterned silicon wafer) with well-defined hierarchical structures [62]. Then, PDMS replicas (stamps), exploiting the principle of the "soft lithography" technique, can be used to fabricate superhydrophobic and functional polymeric composite films; as in the case where waterborne polymer suspensions were directly cast onto the PDMS stamps negatively replicated from fresh plant leaves [63]. Taking advantage of the hydrophobic properties of PDMS, microstructured and superhydrophobic surfaces have been also prepared by direct roughening of PDMS surfaces, achieved by various methods including replication of textured surfaces (e.g., plant leaves, fish skins, artificial molds), lithography or laser etching [54].

Superhydrophobic surfaces can be prepared by chemical vapor deposition (CVD) of PDMS. The CVD process provides a coating over the entire surface of the porous material caused by the thermal degradation of PDMS which leads to a mixture of volatile, low-molecular-weight products [64].

\subsubsection{Silanes and Silicones}

It was found that not only PDMS but also other silicones could be used as the precursor for the superhydrophobic coating [65,66]. Alkylchlorosilanes, alkylalkoxysilanes, perfluoroalkychlorosilanes, and other silanes can be used to decrease the surface energy via CVD or solvent deposition in the preparation of superhydrophobic and superoleophobic surfaces. Aminopropylalkoxysilanes, vinylsilanes, and other silanes with functional groups, assembly of NPs modified with different silanes, PDMS, and silicones can be used as binders between the substrates and coatings [54]. Silanes and silicones play several roles in superhydrophobicity and superoleophobicity simultaneously. On the one hand, the reactive groups of hydrolyzed silanes and silicones through cross-linking with each other can form certain roughness at multiple scales. On the other hand, the alkyl or perfloroalkyl groups of silanes decrease the surface tension, while other active sites can be used for further modification. For the simultaneous construction of micro-/nanostructures and decrease of surface energy, a single silane or silicone via a one-step process or mixture of silanes and silicones via a one-step or multi-step process can be used [54]. Silanes and silicones may also be used simultaneously as binders and for low surface energy materials. Likewise, mixtures of silanes can be used as binders and simultaneous decreasing of surface energy for ensuring nanometric roughness. The frequently used mixtures are composed 
of tetraethyl orthosilicate (TEOS) and, alternatively, different silanes such as perfluoroalkylsilanes and alkylalkoxysilanes.

\subsubsection{Titania Nanoparticles}

Similar to $\mathrm{SiO}_{2} \mathrm{NPs}, \mathrm{TiO}_{2} \mathrm{NPs}$ are also very popular in preparing surfaces with special wettability (i.e., superhydrophobic and superhydrophilic), and they have been widely used to generate superhydrophobic surfaces with both low and high adhesion $[67,68]$. Owing to their unique electronic and optical properties, many synthetic routes are suggested for synthesizing nano- $\mathrm{TiO}_{2}$, among which sol-gel, hydrothermal, and solvothermal methods are more frequently exploited [69]. In the fabrication of $\mathrm{TiO}_{2}$-based nanocomposite, a hydrophobic component is usually necessary due to the hydrophilic nature of $\mathrm{TiO}_{2}$ [70]. $\mathrm{TiO}_{2}$-based super-antiwetting surfaces can be multifunctional in addition to superhydrophobic self-cleaning properties, since they possess photocatalytic property which renders surfaces with anti-fouling and de-polluting characteristics [70,71].

\subsection{Fabrication Methods}

The main approaches for preparing superhydrophobic surfaces can be divided into top-down and bottom-up strategies [31,33]. The former uses lithography, etching, and other methods, such as photolithography, the template method, and plasma treatment method, to prepare multi-layer, micro-rough structures on the surface of the substrate [72-74]. On the contrary, the latter mainly involves self-assembly and self-organization methods (e.g., chemical deposition, layer-by-layer assembly, colloidal self-assembly, sol-gel, etc.), which control the microstructure and surface free energy of the material at an atomic or molecular level $[75,76]$. Yet, some researchers tend to distinguish these approaches on the basis of the chemical or physical nature of the method [31]. These preparation methods have both advantages and disadvantages depending on the field of application. Here, only the methods that have been proved to be more appropriate and efficient for fabricating surfaces for stone conservation are considered.

\subsubsection{Sol-gel}

The sol-gel method is essentially based on chemical processes which exploits a reactive precursor (alkoxy derivatives of metals, metal alkoxide, etc.) to carry out hydrolysis and condensation reactions in a suitable solvent. The materials used in this method can be applied with different methods, as shown in the following sections. During the sol-gel process, a transparent, stable sol is formed firstly, and then the sol polymerizes on the surface of the substrate to form a gel network, which becomes a nanoscale microstructure spontaneously after drying. Both surface roughness and surface chemistry can be controlled by changing preparation conditions and reactants. For instance, superhydrophobic surfaces can be made by changing the functional groups of the gel or by dispersing the low surface energy material into the gel network. Sol-gel methods are widely used in the preparation of ultra-liquid repellence surfaces for a variety of substrates, such as metals, silicon wafers, textiles, woods, stones, etc. Wang et al. reported an effective way of generating superhydrophobicity on various substrates e.g., textiles, papers, glass, etc. [77]. The coating material was fluorine-containing silica sol, which was prepared by the hydrolysis and co-condensation of TEOS and fluorosilane (FAS) in ammonia-ethanol solution (Figure 3). On the coated substrate, the silica NPs successfully constructed a rough surface with nanometer scales, whilst the fluorine-containing branch of the surface acted as a low surface energy material, giving rise to superhydrophobic and self-cleaning properties. 


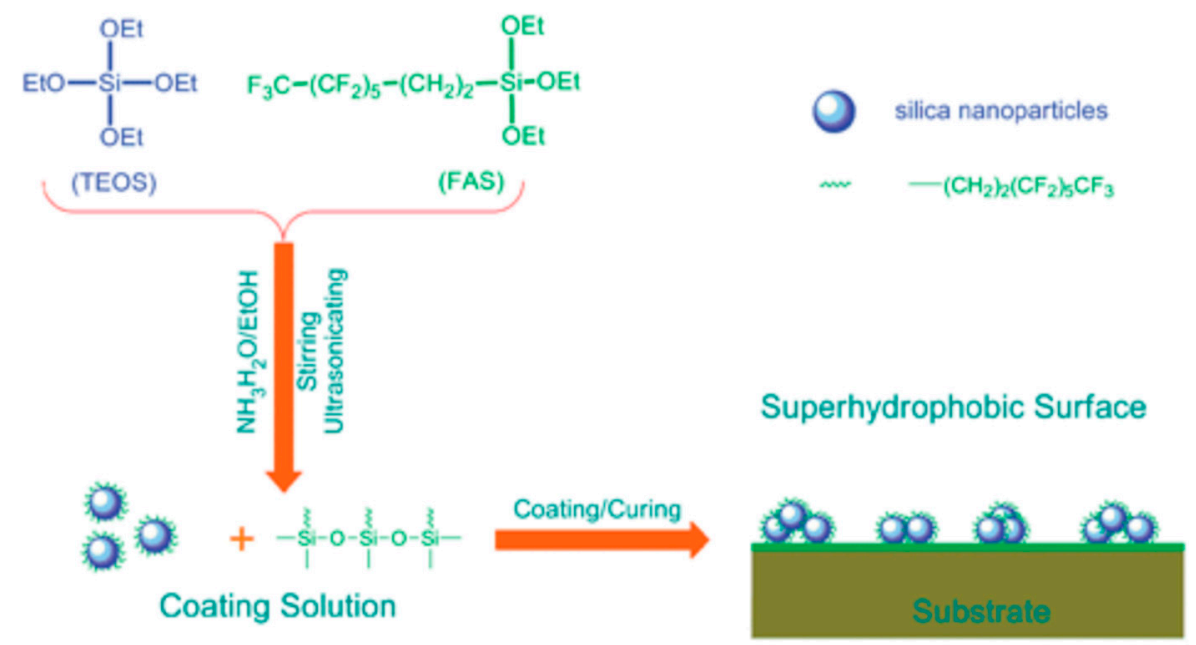

Figure 3. Schematic illustration of the synthesis of fluorinated silica NPs, and the corresponding coating formed. Reprinted with permission from [77], Copyright (2008) Royal Society of Chemistry.

\subsubsection{Layer-by-Layer Assembly}

This method uses thin films (or layers), especially oppositely charged films, to construct a superhydrophobic material. A typical preparation of the layer-by-layer (LbL) assembly consists of an alternate immersion of the substrate in a positively or negatively charged solution to adsorb the charged material sequentially [33]. The removal of the excess or remaining solution, after each step, is done by solvent rinsing which leaves a thin layer of charged material on the surface for subsequent adsorption. The connection between the layers can be achieved by various forces, such as electrostatic attraction, hydrogen bonding, coordination bonds, charge transfer, and characteristic molecular recognition. This method can also be used for the assembly of nanoparticles, for example, using different functionalized $\mathrm{SiO}_{2} \mathrm{NPs}$ to make a composite surface with a layered structure, followed by hydrophobization of the last layer to reduce the wettability of the surface $[78,79]$. In general, the hydrophobicity of the surface is determined by the number of layers of $\mathrm{SiO}_{2} \mathrm{NPs}$ and the surface topology. As shown in Figure 4, Tsai et al. produced a superhydrophobic nanocoating, which has a raspberry-like structure, by self-assembly of $\mathrm{SiO}_{2} \mathrm{NPs}$ [80]. Firstly, a one-dimensional micro-rough structure was prepared on the substrate by using silica particles with a diameter of $0.5 \mu \mathrm{m}$, and then nanoscale silica particles were assembled on the particle film to form a two-dimensional micro-rough structure. Finally, surface hydrophobization was carried out by using dodecyltrichlorosilane.

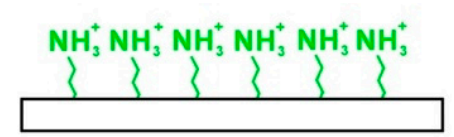

Protonated 3-AMDS modified Glass

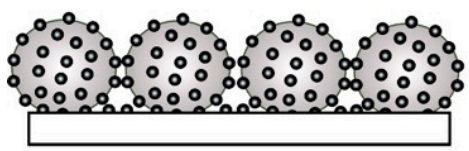

Raspberry-like particulate film

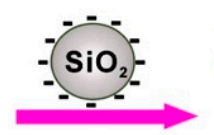

0.5um $\mathrm{SiO}_{2}$
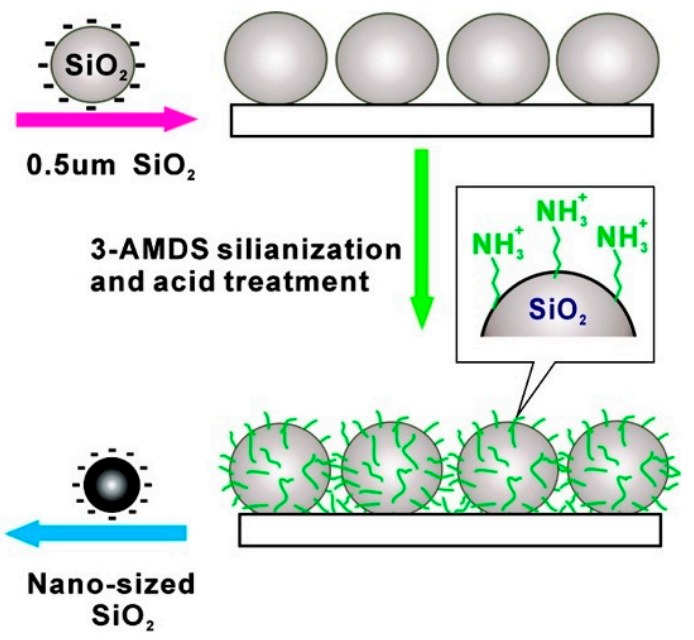

Figure 4. Schematic illustration of the preparation of the raspberry-like nanocomposite coating. Reprinted with permission from [80], Copyright (2007) American Chemical Society. 


\subsubsection{Solution Immersion}

Solution immersion is a very simple method in which the substrate is immersed in a solution containing a low-surface-tension agent to generate superhydrophobicity via one single step. Although the method is easy, it is time-consuming, and the microscopic roughness is not controllable. Zhang et al. constructed a nanocomposite coating on Ramie fiber by using multiwall carbon nanotubes (MWNT) and polybenzoxazine (BOZ) by soaking, washing, and drying processes [81], while other researchers have prepared superhydrophobic surfaces on metal substrates by a one-step immersion method [82].

\subsubsection{Spray}

This is the simplest and most practical way to prepare nanocoatings, even on large surfaces such as those of monumental buildings. The coating is prepared by spraying the coating material dispersion, solution or emulsion directly onto the substrate by using a spray gun. Many studies regarding the spray process have already been published $[83,84]$. Wu et al. prepared a $\left[\mathrm{CH}_{3}\left(\mathrm{CH}_{2}\right)_{10} \mathrm{COO}\right]_{2} \mathrm{Cu}$ superhydrophobic coating on the surface of different substrates, such as glass and aluminium, by spraying the emulsion with nitrogen gas [84]. More recently, spray methods, including the spraying LbL assembly, have focused on studying the adhesion between coatings and substrates, controlling the surface morphology or nanoscale roughness of coatings and tailoring the deposition of layers with defined composition [83-85].

\subsubsection{Other Methods}

Other methods, including chemical etching, laser etching, chemical vapor deposition, physical vapor deposition, lithography, hydrothermal methods, composite techniques, etc., have their own characteristics and corresponding fields of application. Among them, physical or chemical etching methods are more suitable for specific types of substrates, such as silicon wafers, metals, etc.; physical or chemical deposition methods require complex and expensive equipment, and the preparation process is complex and occurs under harsh conditions (e.g., high or low pressure, high temperature, etc.). Hence, their applications are not universally exploited. Aiming to develop advanced materials for art conservation, some basic requirements must be accomplished; for example, the original appearance (artistic, aesthetic) of the cultural objects cannot be impaired after applying protective materials. Moreover, all physical and chemical methods that irreversibly modify the substrate during preparation cannot be adopted, such as chemical etching, laser etching, covalent or ionic LbL assembly. Additionally, the experimental procedure must be simple and easy to perform, in any condition where the cultural surface is present (indoors, outdoors). As a consequence, preparation methods which require extreme experimental conditions (e.g., high temperature and high pressure) such as a chemical vapor deposition method or a hydrothermal method, are not suitable. Methods that are only suitable for substrates with limited dimensions (e.g., solution immersion) are not practical for art conservation. At this stage, the sol-gel method is the most appropriate and convenient method for preparing materials for conservation, since it has several indispensable advantages: (1) availability of a wide variety of raw materials; (2) low cost of raw materials, (3) simple reaction conditions and equipment; (4) no physical or chemical modification of the substrate, (5) application process can be carried out in indoor and outdoor environments, (6) application can be done by simple methods such as spraying and brushing. All these characteristics meet the basic requirements for conservation and restoration practices.

\section{Superhydrophobic Materials Proposed for Stone Conservation}

\subsection{Working Mechanisms of Superhydrophobic Materials for Stone Conservation}

Self-cleaning is one of the most significant applications of superhydrophobic surfaces which demonstrate ultralow surface adhesion, typically known as the "lotus-effect". On a common hydrophobic surface, the droplets slowly fall across the dirt particles, and the attached particles are mainly re-distributed and redeposited behind the droplet, due to the non-slip boundary condition 
(Figure 5) [26,70]. On superhydrophobic surfaces, since there is very small interfacial area between the particle and rough surface (where air is trapped inside), adhesion between solid particles and surface is minimized [26]. Water forms a spherical droplet that quickly runs over the surface, collects dust and dirt particles, and rolls off easily. This specific property prevents surface contamination and is referred to as "self-cleaning".
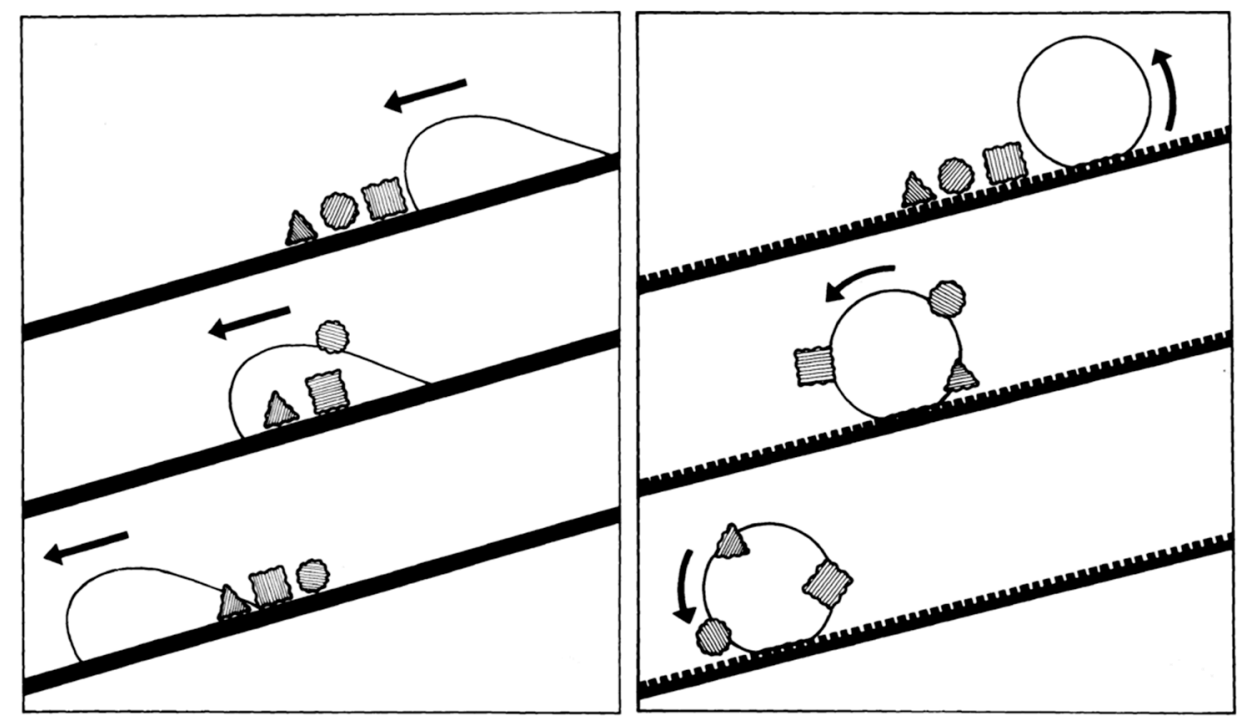

Figure 5. Schematic illustration of the working mechanism of the self-cleaning effect. Reprinted with permission from [26], Copyright (1997) Springer.

Bioinspired ultra water-/oil-repellent surfaces with a self-cleaning property are the most ideal materials for protecting almost all kinds of stones artworks (e.g., stone objects, historical buildings, mortars, plasters, etc.), and the reasons are threefold: (1) liquid water adhesion, penetration, and vapor condensation are inhibited on such surfaces, and water-driven damaging effects are therefore prevented; (2) undesirable surface depositions e.g., atmospheric pollutants, dust, bird droppings, etc., can be removed, exploiting the self-cleaning properties in the presence of liquid water; (3) risks of suffering from biological colonization are dramatically reduced, since spores and pollen are absent or deprived of water which is necessary for germination. Equipped with such surfaces, the physical and chemical integrity together with the aesthetic properties of stone heritage objects can be well maintained.

\subsection{Materials Proposed for Stone Conservation}

In the literature, some hydrophobic materials which can produce surfaces with a "lotus effect" behavior have been synthesized and proposed for building stones, including stone artefacts. Mosquera et al. reported the fabrication of a superhydrophobic coating on sandstone via a sol-gel process [86]. The starting sol was prepared by mixing ethoxysilanes (TES $40 \mathrm{WN}$ from Wacker), colloidal silica particles, and a hydroxyl-terminated polydimethylsiloxane (PDMS) in the presence of a surfactant (n-octylamine). The sol obtained was then applied to sandstone surfaces by brushing. The as-prepared surface had a water CA of $149 \pm 2^{\circ}$ and CAH of $7 \pm 1^{\circ}$ (Table 1 ), showing better performance than a commercial product (BS290) and the nanocomposite without colloidal silica particles (UCA-TP). The amount of water absorbed by stone after coating was dramatically reduced, and water did not penetrate into the stone after immersion for $48 \mathrm{~h}$. The coating also preserved the aesthetic features of stone substrates. However, the amount of coating material applied, which affected the performance of the coating, was not reported, and the vapor diffusivity of the stone after coating was not evaluated. Generally, these two parameters are related one to another: the higher the amount of coating, lower the vapor diffusivity. Therefore, with a very high amount of coating material introduced, superhydrophobicity can be achieved, but simultaneously, the open pore network could be damaged 
which induces severe reduction of vapor diffusivity. A drastic loss of vapor diffusivity facilitates water condensation below the coating layer, which consequently accelerates a series of physical decay effects such as freeze-thaw cycles, differential stress, salt recrystallization, etc. In addition, the minimum amount of active product required for achieving superhydrophobicity also has a great influence on the cost in practical application.

Table 1. Static contact angle (CA) values and contact angle hysteresis (CAH) for untreated and treated stones as reworked from [86]. Adapted with permission from [86], copyright (2013) American Chemical Society.

\begin{tabular}{cccc}
\hline Product & Chemical Composition & Static CA $\left(^{\circ}\right)$ & $\begin{array}{c}\text { Hysteresis } \\
\text { (CAH) }\end{array}$ \\
\hline Untreated & - & $14 \pm 2$ & - \\
BS290 & Silane, siloxane mixture from Wacker & $131 \pm 11$ & $22 \pm 3$ \\
UCA-TP & TES 40 EN, PMDS, and surfactant & $140 \pm 3$ & $13 \pm 1$ \\
UCA-TPS & TES 40 EN, PMDS, surfactant, and & $149 \pm 2$ & $7 \pm 1$ \\
\hline
\end{tabular}

In 2008, Karapanagiotis et al. reported the fabrication of superhydrophobic surfaces from a polymer-nanoparticle suspension composed of silica NPs, polymethylmethacrylate (PMMA) or polyalkylsiloxane (Rhodorsil 224) [87]. The coating was formed by simply spraying the suspension on various substrates, i.e., silicon, glass, silk, aluminium, wood, marble, and concrete. The effect of silica NPs was assessed by varying the concentration (i.e., 0.1, 0.3, 0.5, 1.0, 1.5, and 2.0\%) (Figure 6). The as-prepared surfaces showed water CA values ranging from $154-164^{\circ}$, together with CAH ranging from $3-5^{\circ}$. Similar to the example mentioned above, the exact amounts of coating materials applied were not reported, even if the authors stated that the spray time was relevant to produce films with appropriate performance. Likewise, the vapor diffusivity variation of porous substrates (e.g., marble and concrete) before and after coating was not evaluated. Later, Karapanagiotis et al. prepared an emulsion with a water-soluble siloxane and silica NPs $(7 \mathrm{~nm})$ to spry on marble and sandstone surfaces [88]. The as-prepared surface showed water and oil CA $>150^{\circ}$ with tilting angle $<7^{\circ}$, exhibiting superamphiphobic and self-cleaning properties. It was also demonstrated that the structure of the coatings dramatically changed from a continuous rough structure when the concentration of NP of silica was less than $2 \%(w / w)$ to a network of increasingly large grooves as the concentration of NPs exceeded $2 \%$. These grooves did not influence the static CA, but they were responsible for the transition from the Cassie-Baxter state to the Wenzel state of liquids with low surface tension (e.g., oil, ethylene, glycol drops). Subsequent monitoring of water evaporation showed the drops followed the constant CA model (Figure 7), which was in agreement with the superhydrophobic surface with low surface adhesion. This sol-gel process was very simple, and the application method (spray) was also easy to handle, showing good potential in practical application. As for previous publications, the authors did not evaluate the vapor diffusivity change after coating, but fixed the application conditions (i.e., amount of applied dispersion, diameter of nozzle, distance from the sample surface). Besides, to manifest the versatility of these coatings, application on stones with high porosity, e.g., calcarenite and tuff, ought to be tested. Moreover, in order to be applied in outdoor environments, the resistance of as-prepared coatings against mechanical abrasion, chemical corrosion, and environmental weathering must be assessed. 


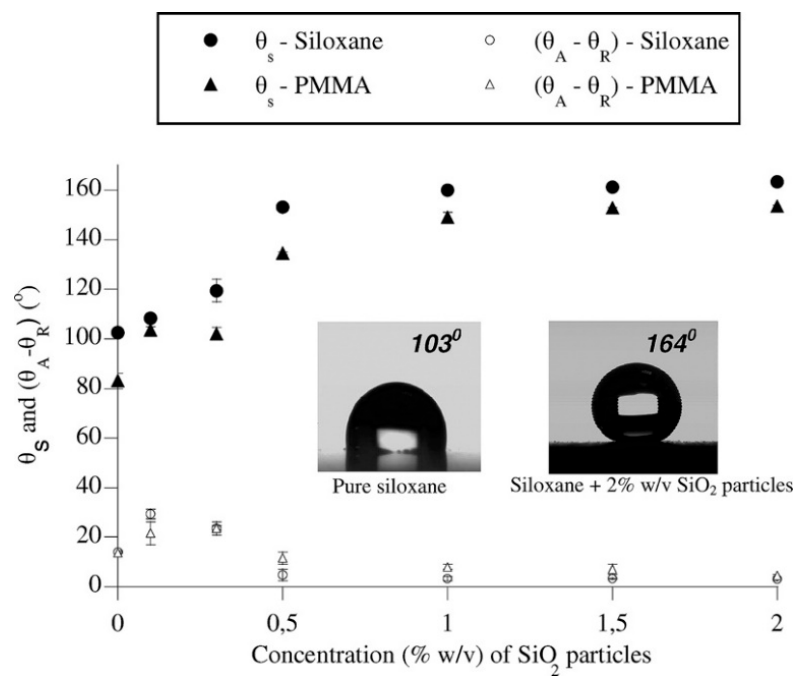

Figure 6. Static contact angle $(\theta s)$ and contact angle hysteresis $\left(\theta_{A}-\theta_{R}\right)$ vs. the concentration of $\mathrm{SiO}_{2}$ particles. Photographs that show measurements of $\theta$ s on pure siloxane (Rhodorsil) and siloxane with $2 \% w / v \mathrm{SiO}_{2}$ particles are included. Reprinted with permission from [87], Copyright (2008) American Chemical Society.

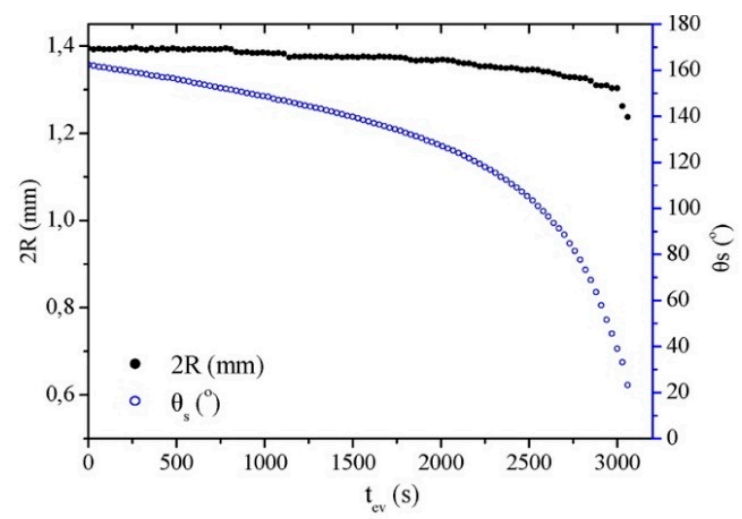

(a)

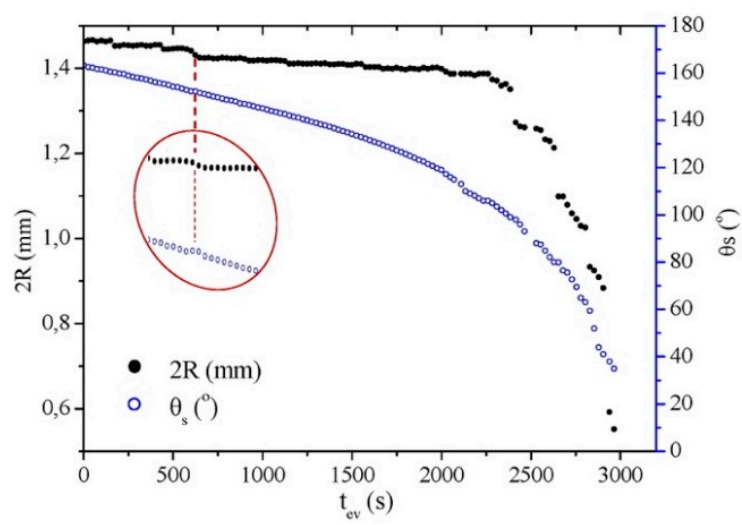

(b)

Figure 7. Contact angle $\left(\theta_{S}\right)$ and contact diameter (2R) of water drops on treated (a) marble and (b) sandstone surfaces vs. evaporation time $\left(t_{e v}\right)$. Marble and sandstone were coated with the emulsion siloxane $+2 \% w / w \mathrm{SiO}_{2}$. In (b), the results recorded at a depinning point of the contact line are magnified to clearly demonstrate the decrease in $\mathrm{R}$ and the slight temporary increase in $\theta_{\mathrm{S}}$. Reprinted with permission from [88], Copyright (2016) Elsevier. 
Cappelletti et al. also reported a sol-gel method to produce superhydrophobic surfaces on various stones [89]. The sol was prepared by mixing a sol of $\mathrm{TiO}_{2} \mathrm{NPs}$ containing a non-ionic surfactant with a silane polysiloxane (Alpha SI30) with a varied weight percentage of polysilixane/ $/ \mathrm{TiO}_{2}$ sol. The coatings were applied by spraying the mixture on the stone surfaces under controlled conditions (fixed spray pressure and spray time). Superhydrophobicity was only observed on Carrara marble surfaces with a water $\mathrm{CA}>150^{\circ}$, while the $\mathrm{CAH}$ was not measured, omitting to indicate the adhesive or slippery property of this coating. Again, the residual vapor diffusivity of the coated rocks was not considered. Instead, the resistance of the coatings to environmental weathering and artificial UV exposure was proved. However, further in-depth testing of as-prepared coatings, in terms of performance on stones with higher porosity, inhibition efficiency against long-term capillary absorption, and strength against chemical and mechanical damage, is expected.

Recently, we developed several innovative coatings based on different partially fluorinated oligoamides (e.g., oligo ethylene-succinamide, -adipamide or -suberamide with two pendant perfluoropolyether segments), which have good solubility in alcoholic and hydro-alcoholic solvents and can be easily applied by common methods (i.e., brush or spray) [18-20]. The as-prepared coatings manifested near superamphiphobicity (water $\mathrm{CA}>150^{\circ}$ and oil CA $>140^{\circ}$ ) on highly porous Lecce stone, yet the surfaces also possessed a high adhesion property $\left(\mathrm{CAH}>90^{\circ}\right)$. The self-cleaning function was not achieved, since water droplets could pin tightly on surfaces even when the substrates were turned upside down. These sticky surfaces showed good application prospects in other fields such as dew collection, non-loss liquid transport, sticky tape, etc. However, as explained previously, to better preserve outdoor stone materials, the self-cleaning property is considered essential in order to eliminate dust, dirt, pollutants, and pollen accumulation and to eradicate black crusts and biological growth. Another desired property for the conservation of cultural heritage surfaces is the superoleophobicity. Though super oil-repellent surfaces are not common in nature, superoleophobicity can be achieved artificially by preferentially adopting fluorinated or perfluorinated compounds [90-93]. Unlike some acrylic coatings, which tend to absorb particulate matter and oily dirt from the atmosphere spontaneously and gradually become stained, superoleophobic surfaces are very efficient in reducing the deposition and adsorption of oily and greasy contaminants. When the superhydrophobic and self-cleaning coating is also superoleophobic, the cleanness of substrates is well maintained. Recently, we further developed a superamphiphobic coating agent synthesized via a single step [94]. The coating agent was obtained by reacting an aminosilane with a perfluoroether derivative at room temperature and room pressure. By simply deposing the coating dispersion (in 2-propanol), superamphiphobic surfaces were obtained on natural stones (e.g., carbonate, silicate stones) with low and high porosity, and on artificial stones such as bricks, tiles, and ceramics. On as-prepared surfaces, CA of water, oil, and complex water dispersion systems (e.g., tea, milk, coffee, coke) were all above $150^{\circ}$, whereas $\mathrm{CAH}<10^{\circ}$ (Figure 8), thus demonstrating superamphiphobic and self-cleaning properties. The surface morphology of the as-prepared coating was characterized by scanning electron microscope (SEM) analysis (Figure 9). It is clear that the coating material which has a slender, needle-like structure (diameter $\approx 100 \mathrm{~nm}$ ) had created a nanoscale roughness structure on the porous substrate, satisfying the physical condition for achieving superhydrophobicity. Meanwhile, exploiting the fluorine segregation phenomenon of the coating material at the surface/air interface, the surface energy of the substrate was significantly reduced. These two fundamental conditions work together to generate the superamphiphobicity and self-cleaning properties. In practical tests, the coating was effective in preventing capillary water absorption for a long time, with water inhibition efficacy $>90 \%$ after $24 \mathrm{~h}$ (Table 2). It should be mentioned that the coating also preserved the physical properties of stone substrates, by well maintaining the original water vapor diffusivity, surface color, and pattern. Moreover, the novel coating also demonstrated strong resistance against chemical corrosion, water immersion, mechanical abrasion, and environmental weathering, exhibiting great potential as a protective coating for objects in outdoor environments (including rainy areas and regions where acid rain occurs). 


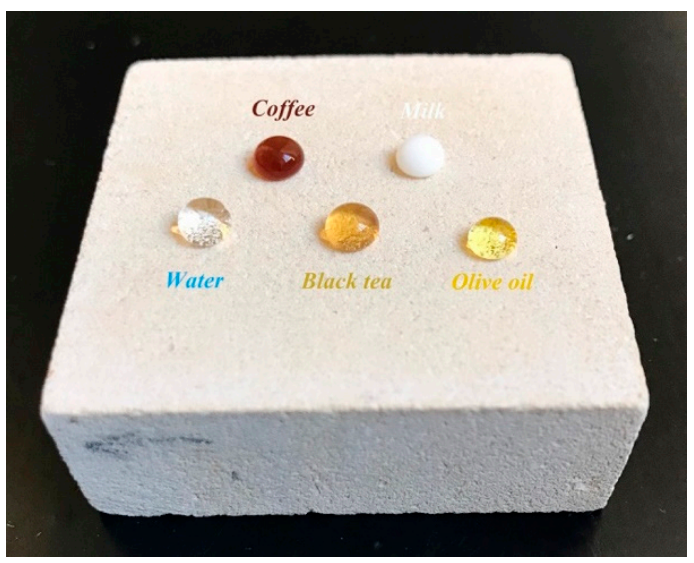

Figure 8. The superamphiphobicity of the as-prepared surface.
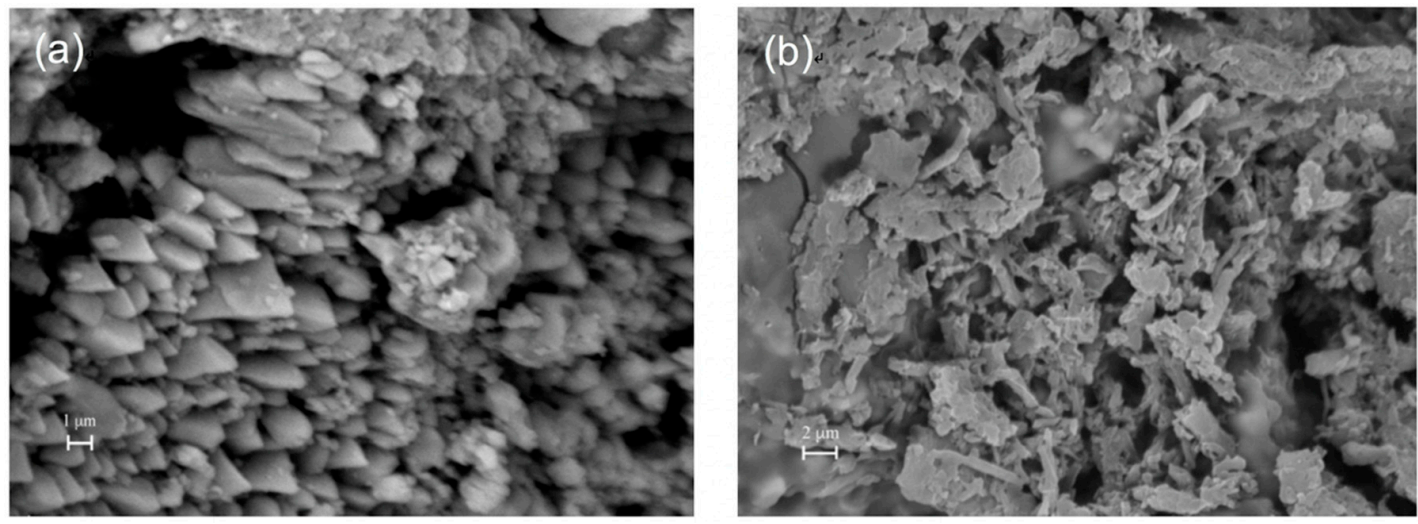

Figure 9. SEM images of a carbonate stone substrate before (a) and after (b) coating.

Table 2. The amount of water absorbed at different absorption times by a carbonate stone before and after coating, and the corresponding inhibition efficiency.

\begin{tabular}{cccc}
\hline \multirow{2}{*}{ Absorption Time (h) } & \multicolumn{2}{c}{ Amount of Water Absorbed (g) } & \multirow{2}{*}{ Inhibition Efficacy (\%) } \\
\cline { 2 - 3 } & $\begin{array}{c}\text { Before } \\
\text { Hydrophobization }\end{array}$ & $\begin{array}{c}\text { After } \\
\text { Hydrophobization }\end{array}$ & \\
\hline 0.5 & 6.92 & 0.09 & 99 \\
1 & 9.79 & 0.15 & 98 \\
2 & 10.12 & 0.26 & 97 \\
24 & 10.30 & 0.80 & 92 \\
\hline
\end{tabular}

There are some other publications presenting the preparation of superhydrophobic coatings for stone maintenance [95-98]. However, similar to the above-mentioned ones, they have both advantages and drawbacks. Their shortcomings in common are: unclear coating amount; unknown vapor diffusivity change after coating; not versatile on stones with both low and high porosity; no in-depth characterization of structure or performance, etc.

\section{Droplet Impact on Superhydrophobic surfaces and Wetting Stability}

Compared with the static non-wetting properties (i.e., CA), studies of dynamic wetting states due to droplet impact on superhydrophobic surfaces are more relevant for practical applications. Indeed, the knowledge of droplet impact dynamics on solid surfaces (both hydrophilic/superhydrophilic and hydrophobic/superhydrophobic) is very important to predict various phenomena encountered in practical applications, including ink-jet printing, internal combustion engines, ice repulsion, waterproof clothing, corrosion protection, self-cleaning [99-108]. 
Depending on the impact kinetics and substrate wetting conditions, several possible patterns for such impingements can be defined: no splashing, prompt splash, corona splash, receding break-up, partial rebound, and complete rebound [104]. For hydrophilic/superhydrophilic surfaces, a no splashing pattern with a complete surface wetting is frequently assumed. However, when the impact velocity of the droplet is within certain limits, water droplets can also bounce off wetting flat surfaces due to the presence of a thin lubricating air layer between the solid surface and the liquid droplet $[109,110]$. On the contrary, for superhydrophobic surfaces with contact angles larger than $150-160^{\circ}$ and with sufficiently large droplet impact velocities, partial or complete bouncing can occur [111]. Generally, when a droplet impacts superhydrophobic surfaces, it firstly spreads to a maximum diameter then recoils to a specific extent and finally can rebound and leave the surface. Contact time (i.e., time between droplet impact and rebound), surface interactions or wettability, internal energy dissipation of the impacting droplet, along with the maximum spreading factor (i.e., the ratio of the maximum spreading diameter and the initial diameter of the droplet) are some important parameters to be considered for characterizing droplet impacts and assessing the performance of superhydrophobic surfaces (e.g., anti-icing and self-cleaning properties) $[107,112-114]$. In particular, the maximum spreading factor can be determined by the well-known Reynolds number $\left(\operatorname{Re}=\rho D_{0} V_{0} / \mu\right)$, Weber number $\left(W e=\rho D_{0} V_{0}^{2} / \sigma\right)$ [115], Ohnesorge number $\left(\mathrm{Oh}=\mathrm{We} e^{1 / 2} / \mathrm{Re}\right)$ [116], and capillary number $(\mathrm{C} a=W e / \mathrm{Re})$ [117], where $\rho, \mu$ represent the density and dynamic viscosity of droplets, respectively, $\sigma$ is the surface tension, $V_{0}$ and $D_{0}$ are the respective initial impact velocity and diameter of the droplet.

In addition, for some specific superhydrophobic surfaces and for high-speed impacts (We > 12), pancake bouncing is observed [118-120]. In this situation, the drop spreads on impact and leaves the surface in a flattened shape without retracting, with a reduction of the contact time (up to five times) compared with conventional rebound. This property is of significant importance for maximizing water repellency.

Moreover, some authors found that the dynamic effects of bouncing water droplets can destroy the composite solid-air-liquid interface, which leads to the transition from the Cassie-Baxter state to the Wenzel state, and proposed a criterion based on the relationship between the impact velocity of the droplet and the parameter of patterned surfaces to predict this transition [121]. Instead, the effects of two types of Cassie-to-Wenzel wetting transitions during drop impact on superhydrophobic surfaces was demonstrated by Lee et al. [122].

Although the effects of droplet impact on superhydrophobic surfaces for the conservation of stone cultural assets can result in unwanted performance, to the best of our knowledge, no studies on this topic have been published. This may be due to the fact that the interest in the fabrication of bioinspired superhydrophobic surfaces is more recent than in other fields of application.

Furthermore, it should be noted that the long-term stability of these special surfaces is also not sufficiently investigated. Indeed, the fabrication of bioinspired superhydrophobic surfaces has attracted many scientists, and great efforts have been devoted to understand the mechanisms which produce this effect, as well as to select materials and methods of fabrication. Therefore, the literature provides many examples of these bioinspired surfaces, which are exploited for many applications, but attention on the stability of wetting properties and durability of the superhydrophobic surfaces has only been taken into consideration recently [123-125].

As the superhydrophobic effect is achieved when well-defined surface energy and micro-nano hierarchical structures conditions are adopted simultaneously, the long-term stability of the wetting property strictly depends on the mechanical robustness and chemical inertia of hydrophobic materials towards aqueous acid, alkaline, salt solutions or organic solvents of the as-prepared superhydrophobic surfaces. Additionally, when applied to everyday life, superhydrophobic surfaces can be damaged by photo- (solar UV irradiation) or thermal degradation of hydrophobic chemicals. Depending on the field of application, most published works focused their attention on improving mechanical robustness [126, 127], antibacterial and anti-biofouling stability [126,128], long-term chemical stability [129-131], adhesion strength [132], and resistance to high-speed drop/jet impact of liquid [133]. Indeed, these 
properties are of primary importance for many applications, such as in surgical instruments, naval construction steel, marine coatings, wind turbine coatings, industrial equipment, fabric coatings, etc.

Typically, the permanence of the superhydrophobic and/or superoleophobic effect is only tested for specific application conditions, and consequently, the tests are limited to a few properties (e.g., mechanical robustness or chemical stability), while standard test methods are rarely employed. Generally, coatings which include inorganic nanoparticles and building blocks usually show mechanical robustness and high chemical susceptibility, whereas organic coatings provide good chemical resistance but poor mechanical stability.

For application in life science and industry, superhydrophobic surfaces are often subjected to harsh conditions, which put in evidence their vulnerability to destruction. For this reason, the testing conditions for these applications are typically strict and sometimes extreme, such as the low speed impact of sand particles [127], high adhesive tape peeling and bending test [126,133], strong acid or alkaline solutions [133], and high temperature exposure [134].

In the field of stone conservation, the as-prepared superhydrophobic surfaces undergo degradation conditions generally less harsh than the materials used in industry. However, mechanical degradation caused by the abrasive effect of sand carried by wind or rain, as well as the photo-oxidative, thermal, and chemical degradation caused by UV irradiation, daily temperature and humidity fluctuations, and acid rain should not be neglected when historic stone surfaces must be preserved for long periods (tens of years or centuries).

As for other fields of application, standard test methods for evaluating the long-term stability of the superhydrophobic effect of the coated stone surfaces are not available. The exposure of the coated stone surfaces to solar-like UV irradiation and natural outdoor conditions [89], as well as artificially accelerated ageing tests where temperature and relative humidity are cyclically varied [135], are the most common methods currently used. These methods are generally employed for testing the durability of common protective treatments for stone cultural assets. Although natural ageing under outdoor conditions is a reliable method for assessing the effective durability in real situations, the long time required for experimentation and the unrepeatable ageing conditions make the tests less practical. Therefore, it is undoubtedly necessary to note that the current methods require integration with additional and properly designed tests to demonstrate the mechanical robustness and chemical stability of the remarkable properties of the superhydrophobic materials.

\section{Conclusion and Future Prospects}

Biomimetic superhydrophobic materials with excellent hydrophobicity, oleophobicity, and a self-cleaning function are efficient protective coatings for heritage conservation. In the current review, we described the basic concepts of superhydrophobicity and the three basic models of wetting on surfaces: Young's model, Wenzel's model, and Cassie's model. Based on the principles of surface hydrophobicity, two general strategies for preparing superhydrophobic/superoleophobic materials were proposed, namely, the method of constructing microscopic roughness on hydrophobic surfaces and the method of adding low surface energy substances on the microscopically coarse surface. There are many physical and chemical methods derived, yet not all of them can be applied for stone conservation. Sol-gel, layer-by-layer assembly, and spray methods have been approved and used for synthesizing materials for stone artworks. Recently, some superhydrophobic and superamphiphobic coating agents have been proposed, and they show good hydrophobicity, oleophobicity, and a self-cleaning property, but they also show some drawbacks which impede the practical application.

Overall, the application of superamphiphobic materials for stone protection is still in the preliminary stage, and few materials have been used in the real case of stone restoration. The main existing problems are as follows: (1) insufficient new compounds; (2) lack of in-depth structure and performance characterization of the modified stone surfaces; (3) lack of long-term performance monitoring of the modified surfaces. Some possible directions for future research in this field that we propose are as follows: 
- Development of more types of superamphiphobic compounds for the varied types of stone materials and varied conditions of application, e.g., high and low porous substrates, smooth- and rough-textured stones, dry and humid environment, etc.

- In-depth evaluation of the properties of the newly synthesized products, as well as of the coated surfaces. Understanding the durability of the superamphiphobicity against chemical corrosion, water immersion, mechanical abrasion, UV exposure, etc., is the first step, and the evaluation of the stability and performance durability of the coated surfaces under harsh, open-air environmental conditions (UV, rain, pollution, etc.) is also desired;

- Understanding the variation of the physicochemical properties of different stone materials after coating with the new products through the evaluation of some important parameters such as vapor diffusivity, porosity, and surface color;

- Development of superamphiphobic, self-cleaning coatings with an anti-biofouling property which can prevent micro-biological growth on outdoor stone surfaces. The interest in this topic is increasing, but few studies have been found in the literature.

Author Contributions: Writing-original draft preparation, Y.C.; writing-review and editing, Y.C., A.S., and M.C.; supervision, M.C.; project administration, M.C. All authors have read and agreed to the published version of the manuscript.

Funding: This research received no external funding.

Conflicts of Interest: The authors declare no conflict of interest.

\section{References}

1. Ruedrich, J.; Kirchner, D.; Siegesmund, S. Physical weathering of building stones induced by freeze-thaw action: A laboratory long-term study. Environ. Earth. Sci. 2011, 63, 1573-1586. [CrossRef]

2. Espinosa-Marzal, R.M.; Scherer, G.W. Advances in understanding damage by salt crystallization. Acc. Chem. Res. 2010, 43, 897-905. [CrossRef] [PubMed]

3. Sabbioni, C. Contribution of atmospheric deposition to the formation of damage layers. Sci. Total Environ. 1995, 167, 49-55. [CrossRef]

4. Pinna, D.; Salvadori, O. Process of biodegradation: General mechanisms. In Plant Biology for Cultural Heritage; Caneva, G., Nugari, M.P., Salvadori, O., Eds.; The Getty Conservation Institute: Los Angeles, CA, USA, 2009; Chapter 2; pp. 15-55.

5. Doehne, E.; Price, C.A. Stone Conservation an Overview of Current Research, 2nd ed.; The Getty Conservation Institute: Los Angeles, CA, USA, 2010; pp. 20-24.

6. Amoroso, G.G.; Camaiti, M. Scienza dei Materiali e Restauro; Alinea Editrice: Florence, Italy, 1997; pp. 119-142.

7. EN 16581:2014. Conservation of Cultural Heritage—Surface Protection for Porous Inorganic Materials—Laboratory Test Methods for the Evaluation of the Performance of Water Repellent Products; BSI: London, UK, 2014.

8. Charola, A.E. Water-repellent treatments for building stones: A practical overview. APT Bull. 1995, 26, 10-17. [CrossRef]

9. Wheeler, G. Alkoxysilanes and the Consolidation of Stone; The Getty Conservation Institute: Los Angeles, CA, USA, 2005; Chapter 1; pp. 1-11.

10. Tabasso, L.M. Acrylic polymers for the conservation of stone: Advantages and drawbacks. APT Bull. 1995, 26, 17-21. [CrossRef]

11. Ciardelli, F.; Aglietto, M.; Castelvetro, V.; Toniolo, L.; Chiantore, O. Fluorinated polymeric materials for the protection of monumental buildings. Macromol. Symp. 2000, 152, 211-222. [CrossRef]

12. Piacenti, F.; Pasetti, A.; Matteoli, U.; Strepparola, E. Method for Protecting Stone Materials from Atmospheric Agents by Means of Perfluoropolyether Derivatives. U.S. Patent 4745009A, 17 May 1988.

13. Piacenti, F.; Camaiti, M. Synthesis and characterization of fluorinated polyetheric amides. J. Fluor. Chem. 1994, 68, 227-235. [CrossRef]

14. Mazzola, M.; Frediani, P.; Bracci, S.; Salvini, A. New strategy for the synthesis of partially fluorinated acrylic polymers as possible materials for the protection of stone monuments. Eur. Polym. J. 2003, 39, 1995-2003. [CrossRef] 
15. Toniolo, L.; Poli, T.; Castelvetro, V.; Manariti, A.; Chiantore, O.; Lazzari, M. Tailoring new fluorinated acrylic copolymers as protective coatings for marble. J. Cult. Herit. 2002, 3, 309-316. [CrossRef]

16. Sadat-Shojai, M.; Ershad-Langroudi, A. Polymeric coatings for protection of historic monument: Opportunities and challenges. J. Appl. Polym. Sci. 2009, 112, 2535-2551. [CrossRef]

17. Striani, R.; Frigione, M.; Corcione, C.E. UV-cured siloxane-modified methacrylic system containing hydroxyapatite as potential protective coating for carbonate stones. Prog. Org. Coat. 2013, 76, 1236-1242.

18. Camaiti, M.; Brizi, L.; Bortolotti, V.; Papacchini, A.; Salvini, A.; Fantazzini, P. An environmental friendly fluorinated oligoamide for producing nonwetting coatings with high performance on porous surfaces. ACS Appl. Mater. Interfaces 2017, 42, 37279-37288. [CrossRef]

19. Cao, Y.; Salvini, A.; Camaiti, M. Oligoamide grafted with perfluoropolyether blocks: A potential protective coating for stone materials. Prog. Org. Coat. 2017, 111, 164-174. [CrossRef]

20. Cao, Y.; Salvini, A.; Camaiti, M. Facile design of "sticky" near superamphiphobic surfaces on highly porous substrate. Mater. Design 2018, 153, 139-152. [CrossRef]

21. Lazzari, M.; Aglietto, M.; Castelvetro, V.; Chiantore, O. Photochemical stability of partially fluorinated acrylic protective coatings IV. Copolymers of 2,2,2-trifluoroethyl methacrylate and methyl $\alpha$-trifluoromethyl acrylate with vinyl ethers. Polym. Degrad. Stab. 2003, 79, 345-351. [CrossRef]

22. Favaro, M.; Mendichi, R.; Ossola, F.; Simon, S.; Tomasin, P.; Vigato, P.A. Evaluation of polymers for conservation treatments of outdoor exposed stone monuments. Part II: Photo-oxidative and salts induced weathering of acrylic-silicone mixtures. Polym. Degrad. Stab. 2007, 92, 335-351. [CrossRef]

23. Melo, M.J.; Bracci, S.; Camaiti, M.; Chiantore, O.; Piacenti, F. Photodegradation of acrylic resins used in conservation of stone. Polym. Degrad. Stab. 1999, 66, 23-30. [CrossRef]

24. Gu, J. Microbiological deterioration and degradation of synthetic polymeric materials: Recent research advances. Int. Biodeterior. Biodegrad. 2003, 52, 69-91. [CrossRef]

25. Cappitelli, F.; Principi, P.; Pedrazzani, R.; Toniolo, L.; Sorlini, C. Bacterial and fungal deterioration of the Milan Cathedral marble treated with protective synthetic resins. Sci. Total Environ. 2007, 385, 172-181. [CrossRef]

26. Barthlott, W.; Neinhuis, C. Purity of the sacred lotus, or escape from contamination in biological surfaces. Planta 1997, 202, 1-8. [CrossRef]

27. Sun, T.; Feng, L.; Gao, X.; Jiang, L. Bioinspired surfaces with special wettability. Acc. Chem. Res. 2005, 38, 644-652. [CrossRef] [PubMed]

28. Hansen, W.R.; Autumn, K. Evidence for self-cleaning in gecko setae. Proc. Natl. Acad. Sci. USA 2005, 102, 385-389. [CrossRef] [PubMed]

29. Feng, L.; Zhang, Y.; Xi, J.; Zhu, Y.; Wang, N.; Xia, F.; Jiang, L. Petal effect: A superhydrophobic state with high adhesive force. Langmuir 2008, 24, 4114-4119. [CrossRef] [PubMed]

30. Li, X.; Reinhoudt, D.; Crego-Calama, M. What do we need for a superhydrophobic surface? A review on the recent progress in the preparation of superhydrophobic surfaces. Chem. Soc. Rev. 2007, 36, 1350-1368. [CrossRef]

31. Zhang, X.; Niu, J.; Jiang, Y.; Wang, Z. Superhydrophobic surfaces: From structural control to functional application. J. Mater. Chem. 2008, 18, 621-633. [CrossRef]

32. Shirtcliffe, N.; McHale, G.; Newton, M. An introduction to superhydrophobicity. Adv. Colloid Interface Sci. 2011, 161, 124-138. [CrossRef]

33. Celia, E.; Darmanin, T.; De Givenchy, E.; Amigoni, S.; Guittard, F. Recent advances in designing superhydrophobic surfaces. J. Colloid Interface Sci. 2013, 402, 1-18. [CrossRef]

34. Chu, Z.; Seeger, S. Superamphiphobic surfaces. Chem. Soc. Rev. 2014, 43, 2784-2798. [CrossRef]

35. Wen, L.; Tian, Y.; Jiang, L. Bio-inspired super-wettability from fundamental research to practical applications. Angew. Chem. Int. Ed. 2015, 54, 3387-3399. [CrossRef]

36. Lu, Y.; Sathasivam, S.; Song, J.; Crick, C.R.; Carmalt, C.J.; Parkin, I.P. Repellent materials. Robust self-cleaning surfaces that function when exposed to either air or oil. Science 2015, 347, 1132-1135. [CrossRef]

37. Genzer, J.; Efimenko, K. Recent developments in superhydrophobic surfaces and their relevance to marine fouling: A review. Biofouling J. Bioadhesion Biofilm Res. 2006, 22, 339-360. [CrossRef] [PubMed]

38. Zhang, Q.; He, M.; Chen, J.; Wang, J.; Song, Y.; Jiang, L. Anti-icing surfaces based on enhanced self-propelled jump of condensed water microdroplets. Chem. Commun. 2013, 49, 4516-4518. [CrossRef] [PubMed] 
39. Ragesh, P.; Ganesh, V.A.; Nair, S.V.; Nair, A.S. A review on 'self-cleaning and multifunctional materials'. J. Mater. Chem. A 2014, 2, 14773-14797. [CrossRef]

40. Xu, Z.; Zhao, Y.; Wang, H.; Wang, X.; Lin, T. A superamphiphobic coating with an ammonia-triggered transition to superhydrophilic and superoleophobic for oil-water separation. Angew. Chem. Int. Ed. 2015, 54, 4527-4530. [CrossRef] [PubMed]

41. Darmanin, T.; Guittard, F. Recent advances in the potential applications of bioinspired superhydrophobic materials. J. Mater. Chem. A 2014, 2, 16319-16359. [CrossRef]

42. Young, T. An essay on the cohesion of fluids. Trans. R. Soc. Lond. 1805, 95, 65-87.

43. Reick, F.G. Substrate Coated with Super-Hydrophobic Layers. U.S. Patent 3931428, 6 January 1976.

44. Wenzel, R.N. Resistance of solid surface to wetting by water. Ind. Eng. Chem. 1936, 28, 988-994. [CrossRef]

45. Cassie, A.B.D.; Baxter, S. Wettability of porous surfaces. Trans. Faraday Soc. 1944, 40, 546-551. [CrossRef]

46. Lafuma, A.; Quere, D. Superhydrophobic states. Nat. Mater. 2003, 2, 457-460. [CrossRef]

47. Reyssat, M.; Yeomans, J.M.; Quere, D. Impairment of fakir drops. Europhys. Lett. 2008, 81, 26006. [CrossRef]

48. Bartolo, D.; Bouamrirene, F.; Verneuil, E.; Buguin, A.; Silberzan, P.; Moulinet, S. Bouncing or sticky droplets: Impalement transitions on superhydrophobic micropatterned surfaces. Europhys. Lett. 2006, 74, $299-305$. [CrossRef]

49. Jung, Y.C.; Bhushan, B. Dynamic effects induced transition of droplets on biomimetic superhydrophobic surfaces. Langmuir 2009, 25, 9208-9218. [CrossRef] [PubMed]

50. Bormashenko, E.; Pogreb, R.; Stein, T.; Whyman, G.; Erlich, M.; Musin, A.; Machavariani, V.; Aurbach, D. Characterization of rough surfaces with vibrated drops. Phys. Chem. Chem. Phys. 2008, 10, 4056-4061. [CrossRef] [PubMed]

51. Koishi, T.; Yasuoka, K.; Fujikawa, S.; Ebisuzaki, T.; Zeng, X. Coexistence and transition between Cassie and Wenzel state on pillared hydrophobic surface. Proc. Natl. Acad. Sci. USA 2009, 106, 8435-8440. [CrossRef] [PubMed]

52. Furmidge, C.G.L. Studies at phase interfaces. I. The sliding of liquid drops on solid surfaces and a theory for spray retention. J. Colloid Sci. 1962, 17, 309-324. [CrossRef]

53. Bayer, I.S.; Megaridis, C.M.; Zhang, J.; Gamota, D.; Biswas, A. Analysis and surface energy estimation of various model polymeric surfaces using contact angle hysteresis. J. Adhes. Sci. Technol. 2007, 21, 1439-1467. [CrossRef]

54. Li, L.; Li, B.; Dong, J.; Zhang, J. Roles of silanes and silicones in forming superhydrophobic and superoleophobic materials. J. Mater. Chem. A 2016, 4, 13677-13725. [CrossRef]

55. Artus, G.R.J.; Jung, S.; Zimmermann, J.; Gautschi, H.P.; Marquardt, K.; Seeger, S. Silicone nanofilaments and their application as superhydrophobic coatings. Adv. Mater. 2006, 18, 2758-2762. [CrossRef]

56. Horiuchi, Y.; Fujiwara, K.; Kamegawa, T.; Mori, K.; Yamashita, H. An efficient method for the creation of a superhydrophobic surface: Ethylene polymerization over self-assembled colloidal silica nanoparticles incorporating single-site Cr-oxide catalysts. J. Mater. Chem. 2011, 21, 8543-8546. [CrossRef]

57. Hsieh, C.; Wu, F.; Chen, W. Superhydrophobicity and superoleophobicity from hierarchical silica sphere stacking layers. Mater. Chem. Phys. 2010, 121, 14-21. [CrossRef]

58. Liang, J.; Wang, L.; He, L.; Sun, S. Pyridine-containing block copolymer/silica core-shell nanoparticles for one-step preparation of superhydrophobic surfaces. Phys. Chem. Chem. Phys. 2013, 15, 10921-10929. [CrossRef] [PubMed]

59. Zhang, C.; Zhang, S.; Gao, P.; Ma, H.; Wei, Q. Superhydrophobic hybridfilms prepared from silica nanoparticles and ionic liquids via layer-by-layer self-assembly. Thin Solid Films 2014, 570, 27-32. [CrossRef]

60. Bayiati, P.; Tserepi, A.; Gogolides, E.; Misiakos, K. Selective plasma-induced deposition of fluorocarbon films on metal surfaces for actuation in microfluidics. J. Vac. Sci. Technol. A 2004, 22, 1546-1551. [CrossRef]

61. Tserepi, A.D.; Vlachopoulou, M.-E.; Gogolides, E. Nanotexturing of poly(dimethylsiloxane) in plasmas for creating robust super-hydrophobic surfaces. Nanotechnology 2006, 17, 3977-3983. [CrossRef]

62. Sun, M.H.; Luo, C.X.; Xu, L.P.; Ji, H.; Qi, O.Y.; Yu, D.P.; Chen, Y. Artificial lotus leaf by nanocasting. Langmuir 2005, 21, 8978-8991. [CrossRef] [PubMed]

63. Feng, J.; Huang, B.; Zhong, M. Fabrication of superhydrophobic and heat-insulating antimony doped tin oxide/polyurethane films by cast replica micromolding. J. Colloid Interface Sci. 2009, 336, 268-272. [CrossRef]

64. Yuan, J.; Liu, X.; Akbulut, O.; Hu, J.; Suib, S.L.; Kong, J.; Stellacci, F. Superwetting nanowire membranes for selective absorption. Nat. Nanotechnol. 2008, 3, 332-336. [CrossRef] 
65. Seyedmehdi, S.A.; Zhang, H.; Zhu, J. Influence of production method, silicone type and thickness on silicon rubber superhydrophobic coatings. Prog. Org. Coat. 2018, 90, 291-295. [CrossRef]

66. Joo, J.; Choun, M.; Kim, K.; Uhm, S.; Kim, Y.D.; Lee, J. Controlled water flooding of polymer electrolyte fuel cells applying superhydrophobic gas diffusion layer. Curr. Appl. Phys. 2014, 14, 1374-1379. [CrossRef]

67. Liu, K.; Cao, M.; Fujishima, A.; Jiang, L. Bio-inspired titanium dioxide materials with special wettability and their applications. Chem. Rev. 2014, 114, 10044-10094. [CrossRef]

68. Lai, Y.; Huang, J.; Cui, Z.; Ge, M.; Zhang, K.Q.; Chen, Z.; Chi, L. Recent advances in $\mathrm{TiO}_{2}$-based nanostructured surfaces with controllable wettability and adhesion. Small 2016, 12, 2203-2224. [CrossRef] [PubMed]

69. Byanvand, M.M.; Kharat, A.N.; Fatholahi, L.; Beiranvand, Z.M. A review on synthesis of nano-TiO 2 via different methods. J. Nanostruct. 2013, 3, 1-9.

70. Kamegawa, T.; Shimizu, Y.; Yamashita, H. Superhydrophobic surfaces with photocatalytic self-cleaning properties by nanocomposite coating of $\mathrm{TiO}_{2}$ and polytetrafluoroethylene. Adv. Mater. 2012, 24, 3697-3700. [CrossRef] [PubMed]

71. Ding, X.; Zhou, S.; Gu, G.; Wu, L. A facile and large-area fabrication method of superhydrophobic self-cleaning fluorinated polysiloxane $/ \mathrm{TiO}_{2}$ nanocomposite coatings with long-term durability. J. Mater. Chem. 2011, 21, 6161-6164. [CrossRef]

72. Darmanin, T.; De Givenchy, E.T.; Amigoni, S.; Guittard, F. Superhydrophobic surfaces by electrochemical processes. Adv. Mater. 2013, 25, 1378-1394. [CrossRef]

73. Pozzato, A.; DalZilio, S.; Fois, G.; Vendramin, D.; Mistura, G.; Belotti, M.; Chen, Y.; Natali, M. Superhydrophobic surfaces fabricated by nanoimprint lithography. Microelectron. Eng. 2006, 83, 884-888. [CrossRef]

74. Woodward, I.; Schofield, W.C.E.; Roucoules, V.; Badyal, J.P.S. Super-hydrophobic surfaces produced by palsma fluorination of polybutadiene films. Langmuir 2013, 19, 3432-3438. [CrossRef]

75. Liao, K.; Wan, A.; Batteas, J.D.; Bergbreiter, D.E. Superhydrophobic surfaces formed using layer-by-layer self-assembly with aminated multiwall carbon nanotubes. Langmuir 2008, 24, 4245-4253. [CrossRef]

76. Wu, X.; Fu, Q.; Kumar, D.; Ho, J.W.C.; Kanhere, P.; Zhou, H.; Chen, Z. Mechanically robust superhydrophobic and superoleophobic coatings derived by sol-gel method. Mater. Design 2006, 89, 1302-1309. [CrossRef]

77. Wang, H.; Fang, J.; Cheng, T.; Ding, J.; Qu, L.; Dai, L.; Wang, X.; Lin, T. One-step coating of fluoro-containing silica nanoparticles for universal generation of surface superhydrophobicity. Chem. Commun. 2008, 877-879. [CrossRef]

78. Amigoni, S.; De Givenchy, E.T.; Dufay, M.; Guittard, F. Covalent layer-by-layer assembled superhydrophobic organic-inorganic hybrid films. Langmuir 2009, 25, 11073-11077. [CrossRef] [PubMed]

79. Li, X.; Du, X.; He, J. Self-cleaning antireflective coatings assembled from peculiar mesoporous silica nanoparticles. Langmuir 2010, 26, 13528-132534. [CrossRef] [PubMed]

80. Tsai, H.; Lee, Y. Facile method to fabricate raspberry-like particulate films for superhydrophobic surfaces. Langmuir 2007, 23, 12687-12692. [CrossRef] [PubMed]

81. Zhang, T.; Yan, H.; Fang, Z.; E, Y.; Wu, T.; Chen, F. Superhydrophobic and conductive properties of carbon nanotubes/polybenzoxazine nanocomposites coated ramie fabric prepared by solution-immersion process. Appl. Surf. Sci. 2014, 309, 218-224. [CrossRef]

82. Xua, J.; Xu, J.; Cao, Y.; Ji, X.; Yan, Y. Fabrication of non-flaking, superhydrophobic surfaces using a one-step solution-immersion process on copper foams. Appl. Surf. Sci. 2013, 286, 220-227. [CrossRef]

83. Li, Y.; Chen, S.; Wu, M.; Sun, J. All spray processes for the fabrication of robust, self-healing, superhydrophobic coatings. Adv. Mater. 2014, 26, 3344-3348. [CrossRef]

84. Wu, W.; Wang, X.; Liu, X.; Zhou, F. Spray-coated fluorine-free superhydrophobic coatings with easy repairability and applicability. ACS Appl. Mater. Interfaces 2009, 1, 1656-1661. [CrossRef]

85. Li, H.; Zhao, Y.; Yuan, X. Facile preparation of superhydrophobic coating by spraying a fluorinated acrylic random copolymer micelle solution. Soft Matter 2013, 9, 1005-1009. [CrossRef]

86. Facio, D.S.; Mosquera, M.J. Simple strategy for producing superhydrophobic nanocomposite coatings in situ on a building substrate. ACS Appl. Mater. Interfaces 2013, 5, 7517-7526. [CrossRef]

87. Manoudis, P.N.; Karapanagiotis, I.; Tsakalof, A.; Zuburtikudis, I.; Panayiotou, C. Superhydrophobic composite films produced on various substrates. Langmuir 2008, 24, 11225-11232. [CrossRef] 
88. Aslanidou, D.; Panayiotou, C.; Karapanagiotis, I. Tuning the wetting properties of siloxane-nanoparticle coatings to induce superhydrophobicity and superoleophobicity for stone protection. Mater Design 2016, 108, 736-744. [CrossRef]

89. Cappelletti, G.; Fermo, P.; Camiloni, M. Smart hybrid coatings for natural stones conservation. Prog. Org. Coat. 2015, 78, 511-516. [CrossRef]

90. Darmanin, T.; Guittard, F. Superhydrophobic and superoleophobic properties in nature. Mater. Today 2015, 18, 273-285. [CrossRef]

91. Kota, K.A.; Kwon, G.; Tuteja, A. The design and applications of superomniphobic surfaces. NPG Asia Mater. 2014, 6, e109. [CrossRef]

92. Tuteja, A.; Choi, W.; Ma, M.L.; Mabry, J.M.; Mazzella, S.A.; Rutledge, G.C.; McKinley, G.H.; Cohen, R.E. Designing superoleophobic surfaces. Science 2007, 318, 1618-1622. [CrossRef]

93. Liu, H.; Wang, Y.; Huang, J.; Chen, Z.; Chen, G.; Lai, Y. Bioinspired surfaces with superamphiphobic properties: Concepts, synthesis, and applications. Adv. Funct. Mater. 2018, 28, 1707415. [CrossRef]

94. Cao, Y. Stone Artifacts Conservation: Synthesis and Study of New Partially Fluorinated Compounds. Ph.D. Thesis, University of Florence, Florence, Italy, 31 October 2018.

95. De Ferri, L.; Lottici, P.P.; Lorenzi, A.; Montenero, A.; Salvioli-Mariani, E. Study of silica nanoparticles-polysiloxane hydrophobic treatments for stone-based monument protection. J. Cult. Herit. 2011, 12, 356-363. [CrossRef]

96. Chatzigrigoriou, A.; Manoudis, P.N.; Karapanagiotis, I. Fabrication of water repellent coatings using waterborne resins for the protection of the cultural heritage. Macromol. Symp. 2013, 331, 158-165. [CrossRef]

97. Manoudis, P.N.; Karapanagiotis, I.; Tsakalof, A.; Zuburtikudis, I.; Kolinkeová, B.; Panayiotou, C. Superhydrophobic films for the protection of outdoor cultural heritage assets. Appl. Phys. A 2009, 97, 351-360. [CrossRef]

98. Manoudis, P.N.; Tsakalof, A.; Karapanagiotis, I.; Zuburtikudis, I.; Panayiotou, C. Fabrication of super-hydrophobic surfaces for enhanced stone protection. Surf. Coat. Technol. 2009, 203, 1322-1328. [CrossRef]

99. Yarin, A.L. Drop impact dynamics: Splashing, spreading, receding, bouncing ... . Annu. Rev. Fluid Mech. 2006, 38, 159-192. [CrossRef]

100. Mishchenko, L.; Hatton, B.; Bahadur, V.; Taylor, J.A.; Krupenkin, T.; Aizenberg, J. Design of ice-free nanostructured surfaces based on repulsion of impacting water droplets. ACS Nano 2010, 4, 7699-7707. [CrossRef] [PubMed]

101. Varanasi, K.K.; Deng, T.; Smith, J.D.; Hsu, M.; Bhate, N. Frost formation and ice adhesion on superhydrophobic surfaces. Appl. Phys. Lett. 2010, 97, 234102. [CrossRef]

102. Antonini, C.; Amirfazli, A.; Marengo, M. Drop impact and wettability: From hydrophilic to superhydrophobic surfaces. Phys. Fluids 2012, 24, 102104. [CrossRef]

103. Gauthier, A.; Symon, S.; Clanet, C.; Quéré, D. Water impacting on superhydrophobic macrotextures. Nat. Commun. 2015, 6, 8001. [CrossRef]

104. Khojasteh, D.; Kazerooni, M.; Salarian, S.; Kamali, R. Droplet impact on superhydrophobic surfaces: A review of recent developments. J. Ind. Eng. Chem. 2016, 42, 1-14. [CrossRef]

105. Cao, M.; Guo, D.; Yu, C.; Li, K.; Liu, M.; Jiang, L. Water-repellent properties of superhydrophobic and lubricant- infused "slippery" surfaces: A brief study on the functions and applications. ACS Appl. Mater. Interfaces 2016, 8, 3615-3623. [CrossRef]

106. De Ruiter, J.; Soto, D.; Varanasi, K.K. Self-peeling of impacting droplets. Nat. Phys. 2018, 14, 35-39. [CrossRef]

107. Xia, Z.; Xiao, Y.; Yang, Z.; Li, L.; Wang, S.; Liu, X.; Tian, Y. Droplet impact on the super-hydrophobic surface with micro-pillar arrays fabricated by hybrid laser ablation and silanization process. Materials 2019, 12, 765. [CrossRef]

108. Kim, S.; Wang, T.; Zhang, L.; Jiang, Y. Droplet impacting dynamics on wettable, rough and slippery oil-infuse surfaces. J. Mech. Sci. Technol. 2020, 34, 219-228. [CrossRef]

109. Chen, L.; Li, Z. Bouncing droplets on nonsuperhydrophobic surfaces. Phys. Rev. E 2010, 82, 016308. [CrossRef] [PubMed]

110. De Ruiter, J.; Lagraauw, R.; Van den Ende, D.; Mugele, F. Wettability-independent bouncing on flat surfaces mediated by thin air films. Nat. Phys. 2014, 11, 48-53. [CrossRef] 
111. Alizadeh, A.; Bahadur, V.; Zhong, S.; Shang, W.; Li, R.; Ruud, J.; Yamada, M.; Ge, L.; Dhinojwala, A.; Sohal, M. Temperature dependent droplet impact dynamics on flat and textured surfaces. Appl. Phys. Lett. 2012, 100, 111601. [CrossRef]

112. Richard, D.; Clanet, C.; Quéré, D. Surface phenomena: Contact time of a bouncing drop. Nature 2002, $417,811$. [CrossRef] [PubMed]

113. Clanet, C.; Béguin, C.; Richard, D.; Quéré, D. Maximal deformation of an impacting drop. J. Fluid Mech. 2004, 517, 199-208. [CrossRef]

114. Bird, J.C.; Dhiman, R.; Kwon, H.-M.; Varanasi, K.K. Reducing the contact time of a bouncing drop. Nature 2013, 503, 385-388. [CrossRef]

115. Ukiwe, C.; Kwok, D.Y. On the maximum spreading diameter of impacting droplets on well-prepared solid surfaces. Langmuir 2005, 21, 666-673. [CrossRef]

116. Asai, A.; Shioya, M.; Hirasawa, J.; Okazaki, T. Impact of an ink drop on paper. J. Imaging Sci. Technol. 1993, 37, 205-207.

117. Li, X.Y.; Mao, L.Q.; Ma, X.H. Dynamic behavior of water droplet impact on microtextured surfaces: The effect of geometrical parameters on anisotropic wetting and the maximum spreading diameter. Langmuir 2013, 29, 1129-1138. [CrossRef]

118. Moevius, L.; Liu, Y.; Wang, Z.; Yeomans, J.M. Pancake bouncing: Simulations and theory and experimental verification. Langmuir 2014, 30, 13021-13032. [CrossRef]

119. Liu, Y.; Moevius, L.; Xu, X.; Qian, T.; Yeomans, J.M.; Wang, Z. Pancake bouncing on superhydrophobic surfaces. Nat. Phys. 2014, 10, 515-519. [CrossRef] [PubMed]

120. Weisensee, P.B.; Tian, J.; Miljkovic, N.; King, W.P. Water droplet impact on elastic superhydrophobic surfaces. Sci. Rep. 2016, 6, 30328. [CrossRef] [PubMed]

121. Jung, Y.C.; Bhushan, B. Dynamic effects of bouncing water droplets on superhydrophobic surfaces. Langmuir 2008, 24, 6262-6269. [CrossRef] [PubMed]

122. Lee, C.; Nam, Y.; Lastakowski, H.; Hur, J.I.; Shin, S.; Biance, A.-L.; Pirat, C.; “CJ” Kim, C.-J.; Ybert, C. Two types of Cassie-to-Wenzel wetting transitions on superhydrophobic surfaces during drop impact. Soft Matter 2015, 11, 4592-4599. [CrossRef] [PubMed]

123. Zhang, D.; Wang, L.; Qian, H.; Li, X. Superhydrophobic surfaces for corrosion protection: A review of recent progresses and future directions. J. Coat. Technol. Res. 2016, 13, 11-29. [CrossRef]

124. Bi, P.; Li, H.; Zhao, G.; Ran, M.; Cao, L.; Guo, H.; Xue, Y. Robust super-hydrophobic coating prepared by electrochemical surface engineering for corrosion protection. Coatings 2019, 9, 452. [CrossRef]

125. Barati Darband, G.; Aliofkhazraei, M.; Khorsand, S.; Sokhanvar, S.; Kaboli, A. Science and engineering of superhydrophobic surfaces: Review of corrosion resistance, chemical and mechanical stability. Arab. J. Chem. 2020, 13, 1763-1802. [CrossRef]

126. Tesler, A.B.; Kim, P.; Kolle, S.; Howell, C.; Ahanotu, O.; Aizenberg, J. Extremely durable biofouling-resistant metallic surfaces based on electrodeposited nanoporous tungstite films on steel. Nat. Commun. 2015, 6, 8649. [CrossRef]

127. Deng, X.; Mammen, L.; Butt, H.-J.; Vollmer, D. Candle soot as a template for a transparent robust superamphiphobic coating. Science 2012, 335, 67-70. [CrossRef]

128. Heinonena, S.; Huttunen-Saarivirta, E.; Nikkanen, J.-P.; Raulio, M.; Priha, O.; Laakso, J.; Storgårds, E.; Levänen, E. Antibacterial properties and chemical stability of superhydrophobic silver-containing surface produced by sol-gel route. Colloid. Surf. A 2014, 453, 149-161. [CrossRef]

129. Du, C.; He, X.; Tian, F.; Bai, X.; Yuan, C. Preparation of superhydrophobic steel surfaces with chemical stability and corrosion. Coatings 2019, 9, 398. [CrossRef]

130. Jing, X.; Guo, Z. Biomimetic super durable and stable surfaces with superhydrophobicity. J. Mater. Chem. A 2018, 6, 16731-16768. [CrossRef]

131. Wang, C.-F.; Wang, Y.-T.; Tung, P.-H.; Kuo, S.-W.; Lin, C.-H.; Sheen, Y.-C.; Chang, F.-C. Stable superhydrophobic polybenzoxazine surfaces over a wide $\mathrm{pH}$ range. Langmuir 2006, 22, 8289-8292. [CrossRef] [PubMed]

132. Steele, A.; Bayer, I.; Loth, E. Adhesion Strength and superhydrophobicity of polyurethane/organoclay nanocomposite coatings. J. Appl. Polym. Sci. 2012, 125, E445-E452. [CrossRef]

133. Peng, C.; Chen, Z.; Tiwari, M.K. All-organic superhydrophobic coatings with mechanochemical robustness and liquid impalement resistance. Nat. Mater. 2018, 17, 355-360. [CrossRef] 
134. Azimi, G.; Dhiman, R.; Kwon, H.-M.; Paxson, A.T.; Varanasi, K.K. Hydrophobicity of rare-earth oxide ceramics. Nat. Mater. 2013, 12, 315-320. [CrossRef]

135. Cao, Y.; Salvini, A.; Camaiti, M. Superhydrophobic fluorinated oligomers as protective agents for outdoor stone artworks. J. Cult. Herit. 2020. [CrossRef] 